\title{
PERSPECTIVE
}

\section{p53 and stress in the ER}

\author{
Elena S. Stavridi ${ }^{1}$ and Thanos D. Halazonetis ${ }^{1,2,3}$ \\ ${ }^{1}$ The Wistar Institute, Philadelphia, Pennsylvania 19104-4268, USA; ${ }^{2}$ Department of Pathology and Laboratory Medicine, \\ School of Medicine, University of Pennsylvania, Philadelphia, Pennsylvania 19104, USA
}

The p53 tumor suppressor is one of the central players in the response of cells to various forms of stress. Clearly, the main form of stress that activates p53 is genotoxic stress in the form of DNA double-strand breaks (DSBs) or stalled DNA replication forks (Kastan et al. 1991; Vogelstein et al. 2000). If left unchecked by p53, genotoxic stress can lead to loss of genomic integrity and cancer development, as exemplified by the phenotype of mice lacking the $p 53$ gene and the high frequency of $p 53$ gene inactivation in human cancer (Hollstein et al. 1991; Donehower et al. 1992). Given these consequences, it is not surprising that $\mathrm{p} 53$ has potent effects in the cells in which it is activated, including apoptosis and irreversible senescence (Yonish-Rouach et al. 1991; Serrano et al. 1997).

The ability of p53 to induce apoptosis and senescence clearly needs to be tightly regulated. Hyperactivation of p53 could compromise organism survival, if too many cells were driven to undergo apoptosis or permanent senescence, as illustrated by the premature aging phenotype of mice expressing a mutant $p 53$ gene that leads to increased p53 activity (Tyner et al. 2002). Accordingly, there are several mechanisms to control p53 activity. Functionally, one of the most important such mechanisms involves the ubiquitin ligase $\mathrm{Mdm} 2$, which participates with p53 in a negative feedback loop: p53 activates transcription of the $m d m 2$ gene, whose protein product then targets p53 for ubiquitin-dependent degradation (Wu et al. 1993; Honda et al. 1997). Thus, any increase in p53 activity is accompanied by increased p53 degradation. This and other mechanisms to control p53 activity can, of course, be overcome by genotoxic stress.

Genotoxic stress can activate p53 through several pathways that typically involve posttranslational modifications of the $\mathrm{N}$ or $\mathrm{C}$ terminus of p53 (Brooks and $\mathrm{Gu}$ 2003; Xu 2003). The ATM protein kinase, which is activated in response to DNA DSBs, is a key player in p53 activation. ATM activates the Chk2 kinase, which in turn phosphorylates p53 on Ser 20, leading to dissociation of p53 from Mdm2 and increased p53 protein levels. A similar pathway is thought to operate in response to replication blocks, although in this case, ATR, an ATM-

${ }^{3}$ Corresponding author.

EMAIL halazonetis@wistar.upenn.edu; FAX (215) 573-9271.

Article and publication are at http://www.genesdev.org/cgi/doi/10.1101/ gad.1181704 related kinase, is activated, and p53 phosphorylation on Ser 20 is most likely mediated by both Chk2 and Chk1 (Abraham 2001; Iliakis et al. 2003).

Modifications within the $\mathrm{C}$ terminus of p53 are numerous and regulate both the functional activity of $\mathrm{p} 53$ and its protein levels. Acetylation of several lysines, including Lys 373, Lys 381, and Lys 382, enhances the transcriptional activity of p53 and also stabilizes the p53 protein, because lysines that are acetylated cannot be ubiquitinated (Brooks and Gu 2003; Xu 2003). Dephosphorylation of Ser 376 is also observed in response to DNA DSBs (Waterman et al. 1998). This dephosphorylation is ATM-dependent and is apparently important for p53 to activate gene transcription and induce cell cycle arrest (Stavridi et al. 2001). Clearly, ATM, being a kinase, does not directly dephosphorylate p53 on Ser 376; however, the identity of the kinase(s) and phosphatase(s) that modify this residue are not known.

Even though p53 probably originated during evolution to respond specifically to genotoxic stress (Nordstrom and Abrams 2000; Derry et al. 2001), cells are exposed to a multitude of stresses. Therefore, the question arises whether cells have developed mechanisms to ensure that p53 activation is restricted to conditions that threaten genomic integrity. Our understanding of the pathways leading to p53 activation suggests that the cells sense that genomic integrity is threatened by the presence of DNA DSBs or stalled replication forks (Abraham 2001; Iliakis et al. 2003). Certainly, stalling of replication forks due to DNA damage is a good indication of a threat to genomic integrity; however, stalling of replication forks due to reasons other than DNA damage or depleted nucleotides may not necessarily be indicative of a threat to genomic integrity. For example, heat shock will slow down most cellular processes, including DNA replication, but heat is not a genotoxic agent. From the perspective of the cell, it is probably not desirable to activate p53 in response to every agent that slows DNA replication, but how cells make these distinctions had not attracted a lot of attention.

The manuscript by the group of A. Koromilas in this issue (Qu et al. 2004) addresses how a specific form of cellular stress inhibits p53 function. The authors examined cells in which an unfolded protein response (UPR) was induced specifically in the endoplasmic reticulum (ER). This type of stress, often referred to as ER stress, was found to inhibit p53, probably to help ensure that 
p53 activation is restricted to agents that induce genotoxic stress.

The ER lumen is the site where secretory proteins adopt their native conformation. The folding process for these proteins is in general quite complicated, because folding of secretory proteins proceeds hand-in-hand with several posttranslational modifications, including most prominently N-linked glycosylation and disulfide bond formation. The accumulation of unfolded proteins above a certain threshold in the ER lumen leads to a response referred to as ER stress (Kaufman 2002; Sitia and Braakman 2003). Experimentally, ER stress can be induced by agents that interfere with the function of ER-resident glycosylases (such as tunicamycin), agents that lower calcium levels in the ER (such as thapsigargin and ionomycin), and agents that inhibit disulfide bond formation. Under more physiological conditions, unfolded proteins accumulate in the ER under conditions of glucose starvation, hypoxia, and increased temperature. Cells have an elaborate quality-control system to ensure that protein folding proceeds normally in the ER and to respond to ER stress. This system involves protein chaperones of the heat shock family that can discriminate between native and nonnative folds. When these chaperones become saturated by unfolded proteins, the ER sensors, ATF6, PERK, and IRE1, become activated, leading to increased synthesis of ER-resident chaperones and folding enzymes and transient suppression of new protein synthesis. Together, these changes restore the balance between newly synthesized unfolded proteins entering the ER and folded proteins being secreted (Kaufman 2002; Sitia and Braakman 2003).

ATF6 is a transcription factor that is responsible for most of the induction of transcription of ER-resident chaperones and folding enzymes observed in response to ER stress (Haze et al. 1999). PERK and IRE1 are protein kinases that are activated in response to ER stress (Sidrauski and Walter 1997; Harding et al. 1999). PERK phosphorylates and inhibits the translation factor eIF$2 \mathrm{~A}$, leading to a decrease in translation of most mRNAs, thus limiting the load of proteins entering the ER lumen. IRE1, in addition to being a protein kinase, also has sitespecific endoribonuclease (RNase) activity. Activation of its protein kinase activity leads to activation of its RNase activity and subsequent processing of the mRNA of the transcription factor XBP1; in turn, an active form of XBP1 is expressed, allowing transcription of genes that facilitate protein folding in the ER, as well as removal of unfolded protein aggregates from the ER. Additional kinases are also activated in response to ER stress. Glycogen synthase kinase-3 $\beta$ (GSK3 $\beta$ ) becomes dephosphorylated on Ser 9 in response to ER stress; this dephosphorylation enhances its ability to phosphorylate various substrates, including the translation factor eIF-2B (Song et al. 2002). Phosphorylation of eIF-2B transiently inhibits mRNA translation, as described above for PERK-dependent eIF-2A phosphorylation (Fig. 1).

In the accompanying manuscript, Qu et al. (2004) reconcile new findings on p53 with several previous observations, leading to a model by which p53 function is

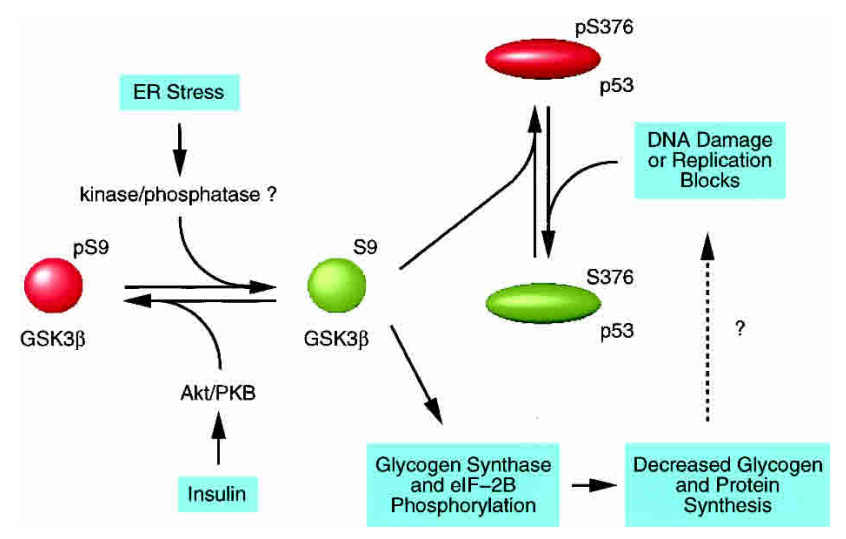

Figure 1. Model for glycogen synthase kinase-3 $\beta$ (GSK3 $\beta$ )-mediated inhibition of p53 by endoplasmic reticulum (ER) stress. ER stress modulates the activity of an as yet unknown kinase or phosphatase, leading to dephosphorylation of GSK3 $\beta$ on Ser 9 (S9). This dephosphorylation enhances the catalytic activity of GSK3 $\beta$, which then directly or indirectly phosphorylates p53 on Ser 376 (pS376), leading to its cytoplasmic sequestration and degradation. GSK3 $\beta$ also phosphorylates glycogen synthase and the translation factor eIF-2B, inhibiting their activities and limiting protein translation. Other pathways that have opposite effects on GSK3 $\beta$ and p53 are also indicated. Insulin, through the kinase Akt/PKB, phosphorylates GSK3 $\beta$ on Ser 9 (pS9; Pearl and Barford 2002; Doble and Woodgett 2003). The DNA damage and replication block checkpoint leads to dephosphorylation of p53 on Ser 376 (S376). The pathway leading to inhibition of p53 in response to ER stress may have evolved to counteract possible (indicated by dotted arrow and question mark) activation of the replication block checkpoint in response to ER stress and decreased protein synthesis. Green and red colors indicate active and inhibited forms, respectively, of GSK3 $\beta$ and p53.

inhibited by ER stress (Fig. 1). First, they demonstrate that ER stress, induced by ER-specific protein folding inhibitors, such as thapsigargin and tunicamycin, or by glucose starvation inhibits the ability of p53 to induce apoptosis in response to DNA damage. They further show that ER stress targets wild-type p53 into the cytoplasm, where it is degraded, providing a mechanistic basis for the inhibition of the apoptotic activity of p53 by ER stress. Finally, they demonstrate a pathway by which ER stress modulates p53 intracellular localization and function. The pathway involves GSK3 $\beta$, which they show can phosphorylate p53 on Ser 376, in cells with ER stress. The functional link between p53 inhibition by ER stress and GSK3 $\beta$ is well-established: in GSK3 $\beta^{-/-}$cells, p53 did not translocate to the cytoplasm in response to ER stress and its apoptotic activity was not inhibited. Furthermore, GSK3 $\beta$ phosphorylates p53 on Ser 376 in vitro, and the function of a p53 mutant with substitution of Ser 376 with Ala is not regulated by ER stress. Based on these findings, the model that emerges is that activation of GSK3 $\beta$ in response to ER stress shifts the equilibrium of p53 phosphorylation on Ser 376 to the phosphorylated state, which in turn facilitates nuclear export, protein degradation, and inhibition of p53 function (Fig. 1). The effect of ER stress on p53 phosphorylation on Ser 376 is opposite to that of the DNA damage check- 
point, which facilitates dephosphorylation and activation of p53 function (Waterman et al. 1998; Stavridi et al. 2001).

The evidence favoring this model is compelling, yet, as the authors point out, certain issues still remain unresolved. The first relates to whether GSK3 $\beta$ directly phosphorylates p53. Mutagenesis of p53 suggests that two sites are important for the change in intracellular localization and inhibition of p53 activity in response to ER stress: one is Ser 376, as described above; the other is Ser 315. Substitution of either of these serines with alanine is sufficient to ablate the effects of ER stress on p53, suggesting that both sites are phosphorylated in vivo. Yet, in vitro, GSK3 $\beta$ phosphorylates only Ser 376 . Furthermore, none of these sites matches the consensus site for GSK3 $\beta$ substrates. Specifically, GSK3 $\beta$ phosphorylates serines or threonines that are marked by a phosphorylated serine or threonine at the +4 position (Pearl and Barford 2002; Doble and Woodgett 2003). For example, glycogen synthase, a well-established substrate of GSK3 $\beta$, is initially phosphorylated by casein kinase 2 on Ser 656; this "priming" phosphorylation event then allows GSK3 $\beta$ to phosphorylate glycogen synthase on Ser 652; this latter phosphorylation then allows further phosphorylation on Ser 648; and, in turn, phosphorylation on Ser 644 and on Ser 640 by GSK3 $\beta$. This pattern of serines spaced four residues apart is present in other GSK3 $\beta$ substrates, including $\beta$-catenin, which is initially phosphorylated by casein kinase $1 \alpha$ on Ser 45 , and subsequently by GSK3 $\beta$ on Thr 41, Ser 37, Ser 33, and Ser 29. p53 has a few serines spaced four residues apart, but Ser 315 and Ser 376 do not have a serine or threonine at the +4 position. Therefore, if GSK3 $\beta$ directly phosphorylates p53 in vivo, it would have to be on a site other than Ser 315 or Ser 376 or it would have to be one of the few cases in which GSK3 $\beta$ can phosphorylate a substrate that does not require to be primed by another protein kinase.

The second unresolved issue relates to whether Ser 315 and Ser 376 phosphorylation are necessary and sufficient for the shift in p53 intracellular localization and for the inhibition of p53 function. The answer is probably no. In the absence of ER stress, wild-type p53 localized predominantly in the nucleus (Qu et al. 2004); yet previous work suggests that in the absence of irradiation, Ser 376 is phosphorylated and at least at some phases of the cell cycle Ser 315 is also phosphorylated (Bischoff et al. 1990; Waterman et al. 1998). Thus, Ser 315 and Ser 376 phosphorylation appear to dictate the intracellular localization of p53 only in cells with ER stress, implying that some other posttranslational modification is required. In addition, results obtained with serine-toalanine substitution mutants need to be interpreted cautiously. A single substitution might affect posttranslational modifications at neighboring residues, as illustrated by the examples of glycogen synthase and $\beta$-catenin listed above, in which substitution of the "priming" serine with alanine would abrogate phosphorylation of a total of five residues. In the case of the p53 Ser 376-to-Ala substitution mutant, there is indirect evidence suggesting that Ser 378 fails to be phosphory- lated (Stavridi et al. 2001). Thus, although Ser 315 and Ser 376 are clearly important for ER stress to regulate p53, they are unlikely to be the only p53 residues involved in this pathway. Implicating additional residues in this pathway might also help explain why in the absence of ER stress, GSK3 $\beta$ can activate p53 (Turenne and Price 2001; Watcharasit et al. 2002, 2003), a finding that otherwise appears contradictory to the model proposed by Qu et al. (2004). It would certainly be interesting if the ER stress sensor kinases PERK and IRE1 cooperate with GSK $3 \beta$ in phosphorylating p53 and inhibiting its activity.

What is the physiological significance of inhibiting p53 in response to ER stress? Probably this pathway evolved to restrict the types of stress that can activate p53. It is possible that ER stress and, more broadly, conditions that favor protein unfolding could nonspecifically stall DNA replication leading to p53 activation and apoptosis. Thus, to restrict p53 activation to genotoxic agents, specific pathways that inhibit p53 in response to nongenotoxic stresses evolved. The pathway identified by Qu et al. (2004) inhibits p53 in response to ER stress; other inhibitory pathways are likely to be identified in the future. In a clinical setting the ability of ER stress to inhibit p53 may affect cancer development and the efficacy of therapy. Hypoxia is common in solid tumors, and as mentioned above, is one of the physiological inducers of ER stress (Kaufman 2002). In those tumors that retain the wild-type $p 53$ gene, ER stress may inhibit its function. This would confer resistance to the DNA-damaging agents used to treat cancer. Thus, inhibiting the ER stress response may augment the efficacy of therapy in some patients.

\section{References}

Abraham, R.T. 2001. Cell cycle checkpoint signaling through the ATM and ATR kinases. Genes \& Dev. 15: 2177-2196.

Bischoff, J.R., Friedman, P.N., Marshak, D.R., Prives, C., and Beach, D. 1990. Human p53 is phosphorylated by p60-cdc2 and cyclin B-cdc2. Proc. Nat1. Acad. Sci. 87: 4766-4770.

Brooks, C.L. and Gu, W. 2003. Ubiquitination, phosphorylation and acetylation: The molecular basis for p53 regulation. Curr. Opin. Cell Biol. 15: 164-171.

Derry, W.B., Putzke, A.P., and Rothman, J.H. 2001. Caenorhabditis elegans p53: Role in apoptosis, meiosis, and stress resistance. Science 294: 591-595.

Doble, B.W. and Woodgett, J.R. 2003. GSK-3: Tricks of the trade for a multi-tasking kinase. J. Cell Sci. 116: 1175-1186.

Donehower, L.A., Harvey, M., Slagle, B.L., McArthur, M.J., Montgomery Jr., C.A., Butel, J.S., and Bradley, A. 1992. Mice deficient for p53 are developmentally normal but susceptible to spontaneous tumours. Nature 356: 215-221.

Harding, H.P., Zhang, Y., and Ron, D. 1999. Protein translation and folding are coupled by an endoplasmic-reticulum-resident kinase. Nature 397: 271-274.

Haze, K., Yoshida, H., Yanagi, H., Yura, T., and Mori, K. 1999. Mammalian transcription factor ATF6 is synthesized as a transmembrane protein and activated by proteolysis in response to endoplasmic reticulum stress. Mol. Biol. Cell 10: 3787-3799.

Hollstein, M., Sidransky, D., Vogelstein, B., and Harris, C.C. 
1991. p53 mutations in human cancers. Science 253: 49-53. Honda, R., Tanaka, H., and Yasuda, H. 1997. Oncoprotein MDM2 is a ubiquitin ligase E3 for tumor suppressor p53. FEBS Lett. 420: 25-27.

Iliakis, G., Wang, Y., Guan, J., and Wang, H. 2003. DNA damage checkpoint control in cells exposed to ionizing radiation. Oncogene 22: 5834-5847.

Kastan, M.B., Onyekwere, O., Sidransky, D., Vogelstein, B., and Craig, R.W. 1991. Participation of p53 protein in the cellular response to DNA damage. Cancer Res. 51: 6304-6311.

Kaufman, R.J. 2002. Orchestrating the unfolded protein response in health and disease. J. Clin. Invest. 110: 1389-1398.

Nordstrom, W. and Abrams, J.M. 2000. Guardian ancestry: Fly p53 and damage-inducible apoptosis. Cell Death Differ. 7: 1035-1038.

Pearl, L.H. and Barford, D. 2002. Regulation of protein kinases in insulin, growth factor and Wnt signalling. Curr. Opin. Struct. Biol. 12: 761-767.

Qu, L., Huang, S., Baltzis, D., Rivas-Estilla, A.-M., Pluquet, O., Hatzoglou, M., Koumenis, C., Taya, Y., Yoshimura, A., and Koromilas, A.E. 2004. Endoplasmic reticulum stress induces p53 cytoplasmic localization and prevents p53-dependent apoptosis by a pathway involving glycogen synthase kinase$3 \beta$. Genes \& Dev. (this issue).

Serrano, M., Lin, A.W., McCurrach, M.E., Beach, D., and Lowe, S.W. 1997. Oncogenic ras provokes premature cell senescence associated with accumulation of p53 and p16 $6^{\mathrm{INK} 4 \mathrm{a}}$. Cell 88: 593-602.

Sidrauski, C. and Walter, P. 1997. The transmembrane kinase Irelp is a site-specific endonuclease that initiates mRNA splicing in the unfolded protein response. Cell 90: 10311039.

Sitia, R. and Braakman, I. 2003. Quality control in the endoplasmic reticulum protein factory. Nature 426: 891-894.

Song, L., De Sarno, P., and Jope, R.S. 2002. Central role of glycogen synthase kinase- $3 \beta$ in endoplasmic reticulum stressinduced caspase-3 activation. J. Biol. Chem. 277: 4470144708.

Stavridi, E.S., Chehab, N.H., Malikzay, A., and Halazonetis, T.D. 2001. Substitutions that compromise the ionizing radiation-induced association of $\mathrm{p} 53$ with 14-3-3 proteins also compromise the ability of p53 to induce cell cycle arrest. Cancer Res. 61: 7030-7033.

Turenne, G.A. and Price, B.D. 2001. Glycogen synthase kinase3 $\beta$ phosphorylates serine 33 of p53 and activates p53's transcriptional activity. BMC Cell Biol. 2: 12.

Tyner, S.D., Venkatachalam, S., Choi, J., Jones, S., Ghebranious, N., Igelmann, H., Lu, X., Soron, G., Cooper, B., Brayton, C., et al. 2002. p53 mutant mice that display early ageing-associated phenotypes. Nature 415: 45-53.

Vogelstein, B., Lane, D., and Levine, A.J. 2000. Surfing the p53 network. Nature 408: 307-310.

Watcharasit, P., Bijur, G.N., Zmijewski, J.W., Song, L., Zmijewska, A., Chen, X., Johnson, G.V., and Jope, R.S. 2002. Direct, activating interaction between glycogen synthase kinase-3 $\beta$ and p53 after DNA damage. Proc. Natl. Acad. Sci. 99: 79517955.

Watcharasit, P., Bijur, G.N., Song, L., Zhu, J., Chen, X., and Jope, R.S. 2003. Glycogen synthase kinase-3 $\beta$ (GSK3 $\beta$ ) binds to and promotes the actions of p53. J. Biol. Chem. 278: 4887248879.

Waterman, M.J., Stavridi, E.S., Waterman, J.L., and Halazonetis, T.D. 1998. ATM-dependent activation of p53 involves dephosphorylation and association with 14-3-3 proteins. Nat. Genet. 19: 175-178.

Wu, X., Bayle, J.H., Olson, D., and Levine, A.J. 1993. The p53- mdm-2 autoregulatory feedback loop. Genes \& Dev. 7: 1126-1132.

$\mathrm{Xu}, \mathrm{Y} .2003$. Regulation of p53 responses by post-translational modifications. Cell Death Differ. 10: 400-403.

Yonish-Rouach, E., Resnitzky, D., Lotem, J., Sachs, L., Kimchi, A., and Oren, M. 1991. Wild-type p53 induces apoptosis of myeloid leukaemic cells that is inhibited by interleukin-6. Nature 352: 345-347. 


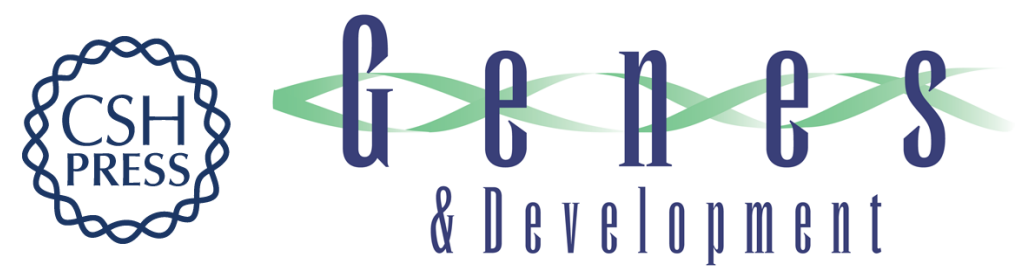

\section{p53 and stress in the ER}

Elena S. Stavridi and Thanos D. Halazonetis

Genes Dev. 2004, 18:

Access the most recent version at doi:10.1101/gad.1181704

References This article cites 29 articles, 12 of which can be accessed free at: http://genesdev.cshlp.org/content/18/3/241.full.html\#ref-list-1

License

Email Alerting Receive free email alerts when new articles cite this article - sign up in the box at the top Service right corner of the article or click here.

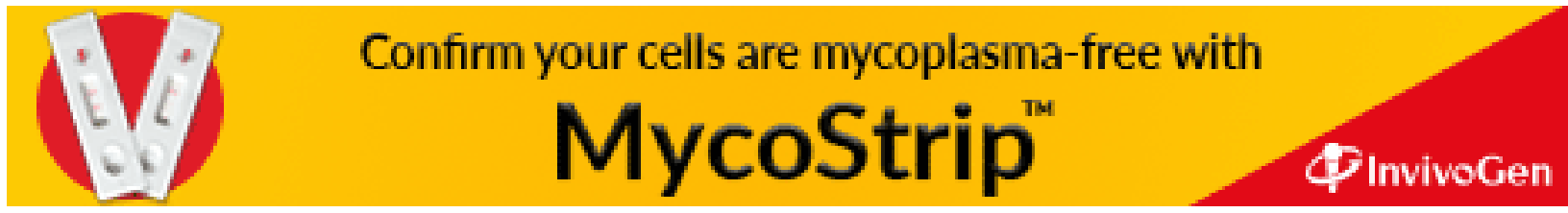

